\title{
Effect of Bumble Bee Pollination on Quality and Yield of Tomato (Solanum lycopersicum Mill.) Grown Under Protected Conditions
}

\author{
Panma Yankit*, Kiran Rana, Harish Kumar Sharma, Meena Thakur and R.K. Thakur
}

Department of Entomology, Dr Y S Parmar University of Horticulture and Forestry, Nauni, Solan, (HP)-173230, India

*Corresponding author

\begin{abstract}
A B S T R A C T
Keywords

Bombus

haemorrhoidalis,

Tomato,

Pollination,

Polyhouse, Bumble

bee

Article Info

Accepted:

04 December 2017

Available Online:

10 January 2018

The effectiveness of the bumble bee Bombus haemorrhoidalis Smith (Hymenoptera: Apidae) was evaluated and compared to non-bumble bee pollinated tomato (Solanum lycopersicum) crop grown under protected conditions. Some qualitative and quantitative characteristics such as day to first fruit harvest, number of fruits, fruit size, in treatments with or without bumble bee colony were recorded. Results based on measurements of mentioned parameters showed highly significant difference. Laboratory reared bumble bee colony utilized for pollination of tomato cultivar (Solan Lalima) grown inside polyhouse resulted in increased number of fruits per cluster (6.76 fruits/cluster), number of fruits (75.80 fruits/plant), fruit length $(5.16 \mathrm{~cm})$, fruit breadth $(5.75 \mathrm{~cm})$, fruit weight $(93.87 \mathrm{~g})$, fruit yield $\left(12.7 \mathrm{~kg} / \mathrm{m}^{2}\right)$ and healthy fruits $(90.33 \%)$. Reduction in number of misshapen fruits $(9.8 \%)$, number of seeds (102.95 seeds/fruit), 1000 seed weight $(6.32 \mathrm{gm})$ over control crop was also observed in bumble bee pollinated crop. Bumble bee pollination accounted per cent increase in number of fruits per plant, healthy fruits, fruit length, fruit breadth, fruit weight, fruit yield, number of seeds and 1000 seed weight by $38.41,21.94$, $46.45,50.82,57.66,64.79,78.54$ and 78.80 per cent, respectively.

\section{Introduction}

Bumble bees are the main pollinators of many plants and have been found pollinating many high value crops. Honey bees also play a vital role in enhancing the productivity but in many crops like tomato, eggplant, cucumber, etc., the bumble bees are more efficient and reliable pollinators especially under protected conditions. Hobbs et al., (1961) found that the bumble bees are the suitable pollinator species to pollinate flowers with deep corolla. In many cases more effective, than manual pollination

or honey bee pollination in terms of the quantity and quality of tomatoes produced. Tomatoes within a greenhouse do not typically achieve adequate pollination without humanintroduced agitation. Until the early 1990s, greenhouse tomato growers have relied on manual pollination of their tomato flowers using hand-held electric vibrators (Banda and Paxton, 1991; Kevan et al., 1991), which can be very time consuming. The use of bumble bee within greenhouses posed an attractive and eventually cost-effective alternative to manual pollination (Velthuis and van Doorn,
\end{abstract}


2006). The growers benefited from bumble bee pollination because of lower production costs, increased yield and improved fruit quality. Bumble bees are the most efficient pollinators not only for the wild plants, but also for pollination services, used in both outdoor and greenhouse horticulture and orchards (Wolf and Moritz, 2008).

Banda and Paxton (1991) reported that bumble bees were effective pollinator of greenhouse tomatoes. Tomatoes were grown in greenhouse in Britain and experiments were under taken to compare the effectiveness of bees in pollinating them. Bumble bees were compared with traditional vibration pollination of tomatoes. The effectiveness of the bees was determined by measuring fruit set, size and weight and seed content. Bumble bees were found to be effective pollinators of greenhouse tomatoes. In Belgium, bumble bee queens introduced in tomato greenhouses resulted in increased productivity up to $70 \%$ (Eijnde et al., 1991).

Abak and Gular (1994) conducted a three year experiment in greenhouse eggplant with bumble bees for effective pollination. It was observed that yield increased by $25 \%$ and the pollinated fruits increased upto $14 \%$ in weight and $7 \%$ in length. Buzz pollination of tomato (Solanum lycopersicum Mill.) by four native species of Japanese bumble bee (Bombus hypocrite, $B$. diversus, $B$. ignites and $B$. ardens) was examined. A high (84-100\%) fruiting rate and almost no puffy fruits $(0-7 \%)$ resulted from pollination by these Japanese bumble bee (Asada and Ono, 1996).

Sanz and Serrano (2006) recorded the bumble bee activity on sweet pepper to determine the fruit quality in greenhouse and found that there is an increase in the seed set per fruit. They recorded $49.8 \%$ and $40.7 \%$ more seed set than the control $(27.5 \%$ and $25.71 \%)$ in two varieties.
In India the studies on effectiveness of bumble bees pollination under protected as well as open conditions are meager and a very few attempts have been made for evaluating the pollination efficiency of bumble bee to boost the production of vegetable crops. Keeping all this view, the present studies were, therefore under taken.

\section{Materials and Methods}

The present studies were carried out at Pandah the experimental farm of the Department of Seed Science and Technology, UHF, NauniSolan, Himachal Pradesh. A $200 \mathrm{~m}^{2}$ polyhouse was selected for experiment. The total area of the polyhouse has been divided into two by using insect proof net in the middle. In one of the portion laboratory reared bumble bee (Bombus haemorrhoidalis Smith) colony (1315) was placed at the time of flowering (5$10 \%$ ) of the crop (Plate 1). While the second portion was control plot (without bumble bee).Tomato crop cultivar Solan Lalima was raised as per package and practices of the university. The spacing was $90 \mathrm{~cm} X 30 \mathrm{~cm}$ from plant to plant and row to row. The data were recorded on ten randomly selected plants for eight replications from both treatment plots (bumble bee pollinated and control plot) for all the productivity and quality characters of the crop.

\section{Results and Discussion}

Bumble bee pollination influenced significantly all the quality and productivity parameters of tomato assessed in this study (Table 1). Bumble bee pollination resulted in higher number of fruits per cluster and plant i.e. 6.76 and 75.80 fruits, respectively as compared to control $(3.33,37.38)$ treatment without bee pollination. Bee pollinated tomato flowers produced tomatoes that were significantly larger in size (fruit length and breadth 5.16 and $5.75 \mathrm{~cm}$, respectively) than 
control treatment and heavier $(93.87 \mathrm{~g})$ than produced from flowers without bee pollination. A noteworthy difference in yield was recorded for both the treatments, control and the bee pollinated plants. The bee pollination treatment recorded significantly higher $\left(12.7 \mathrm{~kg} / \mathrm{m}^{2}\right)$ fruit yield than the control $\left(6.86 \mathrm{~kg} / \mathrm{m}^{2}\right)$ and resulted in an increase of $64.79 \%$ over control (Fig. 1 and Table 2). The number of healthy fruits was also higher in bumble bee pollinated tomato plants (93.33\%) than control (76.54\%). B. haemorrhoidalis pollinated plants accounted 38.41 per cent increase in the number of fruits per plant and 21.9 per cent increase in healthy fruits over control plants. Minimum numbers (9.8) of misshapen were observed in $B$. haemorrhoidalis pollinated plants. Fifty four per cent decrease in number of misshapen fruits was observed in bumble bee pollinated plants as compared to control plants (Fig. 1 and Table 2). The bumble bee treatment recorded significantly higher (102.95) seed number per fruit than control (59.50). Similarly 1000 seed weight was statistically higher $(6.32 \mathrm{~g})$ for bee pollinated tomato than without bee (3.53).
Similarly, an increase in the percentage of fruit length, breadth, fruit weight and fruit yield of tomato were recorded in the crop pollinated by bumble bees and was recorded to be $46.45,50.82,64.94$ and $57.66 \%$, respectively over the crop without bee pollination (control). Simultaneously percent increase in the seed number and weight $(1000$ seeds) was recorded to be 78.54 and 78.80 in bumble bee pollinated plants.

Bumble bee pollination significantly increased the percentage of fruit set (number of fruits per cluster and per plant), fruit size (length and breadth), fruit weight and yield of tomato crop as compared to crop without bee pollination.

Our results indicate that $B$. haemorrhoidalis pollination resulted in enhanced quality and quantity of tomato fruit grown under protected conditions. The data recorded on number of fruits per cluster showed that bumble bees enhanced the number of fruits per cluster and the fruit weight significantly as compared to control (Table 1).

Fig.1 Influence of bumble bee pollination on fruit parameters of tomato over Control (Crop without pollinator)

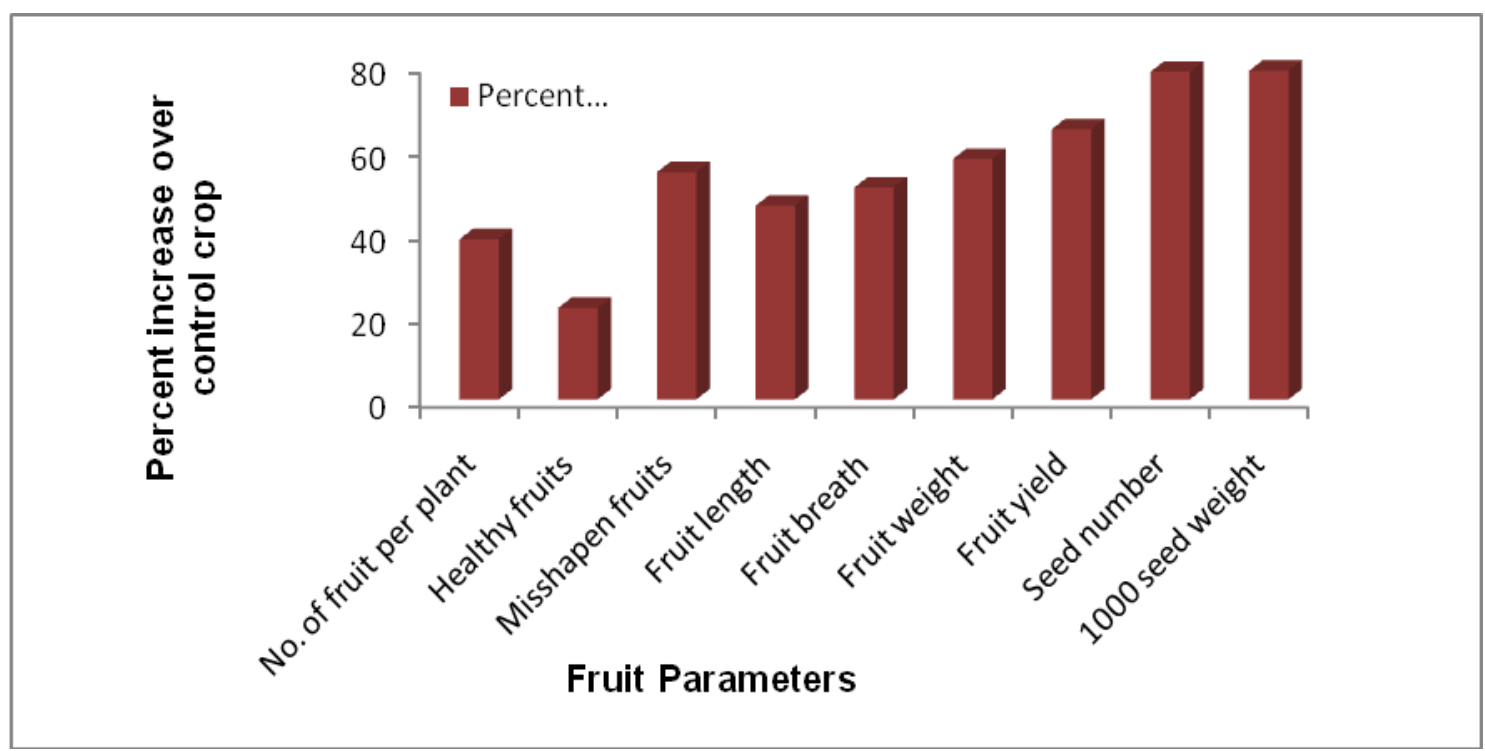




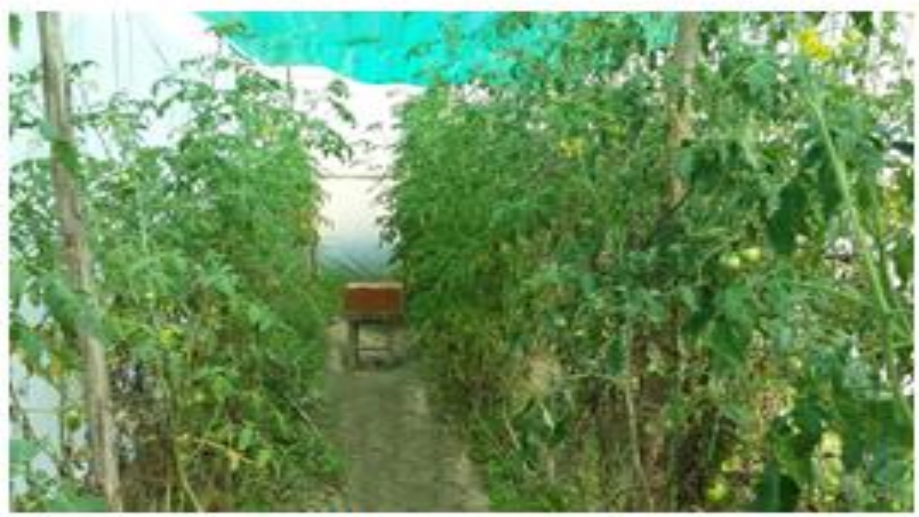

a) $B$. haemorrhoidalis colony inside polyhouse

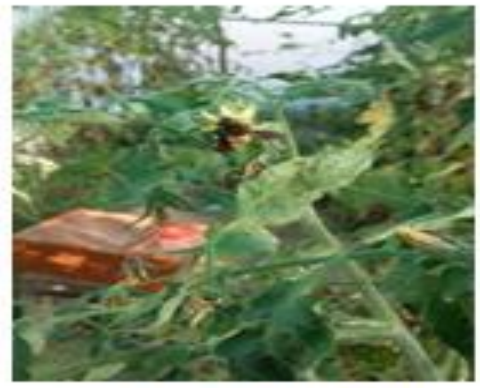

b) B. haemorrhoidats foraging on tomato flower

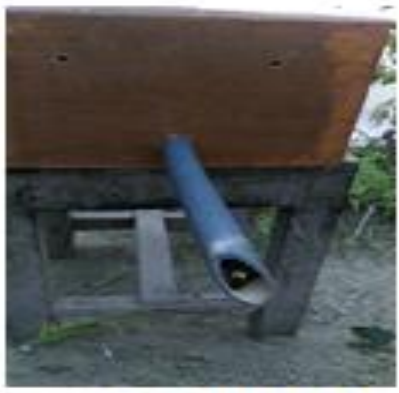

c) Forager coming out from the colony

Plate 1 Laboratory reared $B$. haemorrhoidalis colony shifted to tomato polyhouse for pollination

Table.1 Comparison of Mean \pm S.E number of fruits per cluster, number of fruits per plant, fruit length, fruit breadth, fruit weight, fruit yield, healthy fruits, misshapen fruits, number of seed per fruit and 1000 seed weight between bee pollinated and without bee (control)

\begin{tabular}{|l|}
\hline Parameter \\
\hline Number of fruits per cluster \\
\hline Number of fruits per plant \\
\hline Fruit length (cm) \\
\hline Fruit breadth(cm) \\
\hline Fruit weight $(\mathrm{g})$ \\
\hline Fruit yield $\left(\mathrm{kg} / \mathrm{m}^{2}\right)$ \\
\hline Healthy fruits $(\%)$ \\
\hline Misshapen fruits $(\%)$ \\
\hline Number of seeds per fruit \\
\hline 1000 seed weight (gm) \\
\hline
\end{tabular}

\begin{tabular}{|l|l|}
\hline \multicolumn{2}{|c|}{ Treatment } \\
\hline Bumble Bee Pollination & Control (without bee pollination) \\
\hline $6.76 \pm 0.18$ & $3.33 \pm 0.17$ \\
\hline $75.80 \pm 0.78$ & $37.38 \pm 0.51$ \\
\hline $5.16 \pm 0.49$ & $3.52 \pm 0.133$ \\
\hline $5.75 \pm 0.32$ & $3.81 \pm 0.87$ \\
\hline $93.87 \pm 1.07$ & $59.75 \pm 0.52$ \\
\hline $12.7 \pm 0.12$ & $6.86 \pm 0.22$ \\
\hline $90.33 \pm 4.5$ & $76.54 \pm 2.42$ \\
\hline $9.8 \pm 0.46$ & $22.8 \pm 0.64$ \\
\hline $102.95 \pm 1.52$ & $59.50 \pm 2.08$ \\
\hline $6.32 \pm 0.36$ & $3.53 \pm 0.03$ \\
\hline
\end{tabular}


Table.2 Per cent increase in the quality and productivity parameters of tomato grown under poly house conditions with $B$. haemorrhoidalis pollination

\begin{tabular}{|l|c|}
\hline Quality parameters & Percent increase \\
\hline No. of fruit per plant & 38.41 \\
\hline Healthy fruits & 21.94 \\
\hline Misshapen fruits & $54.49 *$ \\
\hline Fruit length & 46.45 \\
\hline Fruit breadth & 50.82 \\
\hline Fruit weight & 57.66 \\
\hline Fruit yield & 64.79 \\
\hline Seed number & 78.54 \\
\hline 1000 seed weight & 78.80 \\
\hline
\end{tabular}

*Per cent decrease in misshapen fruits

These findings are in agreement with those of Al-Attal et al., (2003) who studied the influence of different pollination techniques on greenhouse tomato production and reported that the average cluster yield and fruit weight were significantly higher in the bumble bee treatment. Dasgan et al., (2004) reported 52.3 and $67.0 \%$ increase in number of fruits by bumble bee pollination over vibration and growth regulator applicators, respectively. In the present studies, the fruit weight and size has been found to be increased in bee pollinated plants compared with control treatment which resulted in small fruits with less weight. Similar results have been reported by Neto et al., (2013) and Hatami et al., (2013) for bumble bee pollination.

Flowers pollinated by bumble bees gave fruits that looked better in shape and were plump without puffiness, harder and of uniform colour. Similar result was shown by Chauhan (2011) who reported less number of crooked fruits in bumble bee pollinated cucumber plants compared to control. Asada and Ono (1996) also reported a high (84-100\%) fruiting rate and almost no puffy fruit $(0-7 \%)$ in bumble bee pollinated tomato crop. The yield increases of bumble bee pollination compared to non-bee pollination have been reported in earlier studies on various vegetables grown under polyhouse viz. cucumber (Chauhan, 2011), eggplant (Abak and Gular, 1994).

In the present study, the data recorded on number of seeds per fruit clearly indicate that bumble bee pollination enhanced the number of seeds significantly as compared to control. These findings are in line with those of Vergara and Buendia (2012) and Neto et al., (2013) who reported more number of seeds in tomato pollinated by B. Ephippiatus (201.00) and (183.94) as compared to control (139.03 and 59.63, respectively) grown inside polyhouse. Similar results were reported by Ahmad et al., (2015) in bumble bee pollination (126 seeds/fruit) as compared to manual pollination (102 seeds/fruit).

Seed count may be the most accurate method for determining levels of pollination because fruit weight is influenced by environmental conditions such as plant resources but not seed count (Picken, 1984). Bee pollination significantly increased seed count over the non-bee pollination treatment indicating that bumble bees are good pollinators. The present investigations clearly indicated that $B$. haemorrhoidalis provides high yield of tomato (variety Solan Lalima) over self- 
pollination (crop without pollinator) under polyhouse conditions with respect to quantitative (number of fruits per cluster, number of fruits per plant, fruit weight, yield, seed number, 1000 seed weight) as well as qualitative (fruit size, and healthy rounder fruit) parameters of tomato seed and fruit. It may be concluded that the bumble bee pollination (B. haemorrhoidalis) in protected condition is better mode of pollination for pollinating tomato crop and should be exploited to enhance the yield and quality of tomato grown under protected condition.

\section{References}

Abak, K., and Guler, H. Y. 1994. Pollen fertility and the vegetative growth of various egg plants genotypes under low temperature conditions. Acta Horticulturae. 366: 85-91.

Ahmad, M., Bodlah, I. Mehmood, K. Sheikh, U. A. A. and Aziz, M. A. 2015. Pollination and foraging potential of European bumble bee, Bombus terrestris (Hymenoptera: Apidae) on tomato Crop under greenhouse system. Pakistan Journal Zoology. 47(5): 12791285.

Al-Attal, Y. Z., Kasrawi, M. A. and Nazer, I. K. 2003. Influence of pollination techniques on greenhouse tomato production. Agricultural and Marine Sciences. 8(1): 21-26.

Asada, S., and Ono, M. 1996. Crop pollination by Japanese bumble bee (Bombusspp.). Tomato foraging behaviour and pollination efficiency. Applied Entomological Zoology. In: Introduction of commercial bumble bees into Japan (Iwasaki M. 1995). Honey bee Science.16: 17-23.

Banda, H. J., and Paxton. 1991. Pollination of greenhouse tomatoes by bees. Acta Horticulturae. 288: 194-198.

Chauhan, A., 2011. Refinement of bumble bee rearing technology and its use in cucumber pollination. M.Sc. Thesis. Dr. Y.S. Parmar University of Horticulture and Forestry, Nauni, Solan, India.

Dasgan, H. Y., Ozdogan, A. O.Kaftanoglu, O. and Abak, K. 2004. Effectiveness of bumblebee pollination in anti-frost heated tomato greenhouses in the Mediterranean basin. Turk Journal Agriculture. 28: 73-82.

Eijnde, J., Ruitjjer, A. and Steen, J. 1991. Method for rearing Bombus terrestris continuously and the production of bumble bee colonies for pollination purposes. Acta Horticulturae. 288: 154158.

Hatami, M., Monfared, A.Haghani, M.and Fahliani, R. A. 2013. Effect of Bombus terrestris L. (Hymenoptera: Apidae) pollinating on flowering and fruiting trends of greenhouse tomato (Lycopersicon esculentum). Linzer biol. Beitr. 45(2): 1907-1919.

Hobbs, G. A., Nummi, W. O. and Virostek, J. F. 1961. Food gathering behavior of honey bees, bumble bees and leaf cutting bees (Hymenoptera: Apoidea) in Alberta. Canadian Entomology. 93: 409-419.

Kevan, P. G., Straver, W. A. Offer, M. and Laverty, T. M. 1991.Pollination of greenhouse tomatoes by bumble bees in Ontario. Proceedings of the Entomological Society of Ontario.122: 15-19.

Neto, C. S., M, Lima, F. G.Goncalves, B. B. Bergamini, L. Bergamini, B. A. R. Elias, M. A. and Franceschinelli, E. V. 2013. Journal of Pollination Ecology. 11(6): 41-45.

Picken, A.J.F., 1984. A review of pollination and fruit set in the tomato (Lycopersicon esculentum Mill.). Journal of Horticulturae Science. 59(1): 1-13.

Sanz, J. M. G., and Serrano, A. R. 
2006.Quality fruit improvement in sweet pepper culture by bumble bee pollination. Scientia Horticulturae. 110(2): 160-166.

Velthuis, H. H. W., and Van Doorn, A. 2006. A century of advances in bumble bee domestication and the economic and environmental aspects of its commercialization for pollination. Apidologie. 37(4): 421-451.
2012. Pollination of greenhouse tomatoes by the Mexican bumblebee Bombus ephippiatus (Hymenoptera: Apidae). Journal of Pollination Ecology. 7(4): 27-30.

Wolf, S., and Moritz, R. F. A. 2008. Foraging distance in Bombus terrestris $\mathrm{L}$. (Hymenoptera: Apidae). Apidologie. 39: 419-427.

Vergara, C. H., and Buendia-Fonseca, P.

\section{How to cite this article:}

Panma Yankit, Kiran Rana, Harish Kumar Sharma, Meena Thakur and Thakur, R.K. 2018. Effect of Bumble Bee Pollination on Quality and Yield of Tomato (Solanum lycopersicum Mill.) Grown Under Protected Conditions. Int.J.Curr.Microbiol.App.Sci. 7(01): 257-263. doi: https://doi.org/10.20546/ijcmas.2018.701.028 